\title{
ANALISIS KESULITAN MAHASISWA PENDIDIKAN MATEMATIKA MENYELESAIKAN SOAL PADA MATA KULIAH KALKULUS I
}

\author{
Fatma Ramadanti ${ }^{1}$, Heni Pujiastuti ${ }^{2}$ \\ ${ }^{1,2}$ Universitas Sultan Ageng Tirtayasa, Jalan Raya Jakarta Indonesia \\ Fatmaramadanti18@gmail.com
}

\begin{abstract}
This research is a qualitative descriptive study. Aiming at describing students' mistakes in solving inequality questions in calculus I. The sample in this study was mathematics education students at Sultan Ageng Tirtayasa University semester 2. Data collection methods used were using the test method and interview method. Before conducting the analysis the researcher examined the validity of the data using triangulation to obtain valid data. Data that was valid were analyzed and then conclusions were obtained. The results showed that sample X made 6 errors, namely errors in determining the results of slices, errors in determining the set of completions, errors in drawing the number line, errors in determining the value of the maker of zeroes, errors in determining the value of the maker of zeroes on the number lines, errors in determining the area of completion of the number lines. Sample Y made 6 errors, namely error in describing the number line, error in determining positive negative on the number line, error in determining the interval sign, error in determining the set of completions, error in determining the area of completion of the number line. The errors of the two samples are almost the same, namely not understanding the concept of inequality and not remembering the basic concept. To avoid continuous mistakes, it is better to learn calculus prioritizing understanding of concepts so that students really understand and understand so that errors in sample X and sample Y do not occur in other students.
\end{abstract}

Keywords: error; Inequality; Analysis; Calculus I

\begin{abstract}
Abstrak
Penelitian ini merupakan penelitian deskriptif kualitatif. Bertujuan mendeskripsikan kesalahan mahasiswa dalam menyelesaikan soal pertidaksamaan pada mata kuliah kalkulus I. Sampel dalam penelitian ini mahasiswa pendidikan matematika Universitas Sultan Ageng Tirtayasa semester 2. Metode pengumpulan data yang digunakan adalah menggunakan metode tes dan metode wawancara. Sebelum melakukan analisis peneliti memeriksa keabsahan data menggunakan triangulasi untuk memperoleh data yang valid. Data yang sudah valid dianalisis kemudian didapat simpulan. Hasil penelitian didapat bahwa sampel X melakukan 6 kesalahan yaitu kesalahan menentukan hasil irisan, kesalahan menentukan himpunan penyelesaian, kesalahan menggambarkan garis bilangan, kesalahan menentukan nilai pembuat nol, kesalahan menentukan nilai pembuat nol pada garis bilangan, kesalahan menentukan daerah penyelesaian garis bilangan. Sampel Y melakukan 6 kesalahan yaitu kesalahan menggambarkan garis bilangan, kesalahan menentukan positif negatif pada garis bilangan, kesalahan menentukan tanda interval, kesalahan menentukan himpunan penyelesaian, kesalahan menentukan daerah penyelesaian garis bilangan. Kesalahan dari kedua sampel hampir sama yaitu kurang memahami konsep pertidaksamaan dan tidak ingat konsep dasar. Untuk menghindari kesalahan secara terus menerus sebaiknya dalam belajar kalkulus utamakan pemahaman konsep agar mahasiswa benar-benar paham dan mengerti sehingga kesalahan pada sampel X dan sampel Y tidak terjadi pada mahasiswa lainnya.
\end{abstract}

Kata Kunci: Kesalahan; Pertidaksamaan; Analisis; Kalkulus I

\section{PENDAHULUAN}

Pendidikan matematika merupakan jurusan yang ada dibeberapa perguruan tinggi. Pendidikan matematika salah satu jurusan yang diminati. Pada pelajaran Sekolah Menengah Atas matematika lebih banyak diberikan pada jurusan IPA sehingga, rata-rata mahasiswa pendidikan matematika berasal dari jurusan IPA. Pelajaran pendidikan matematika yang dipelajari disekolah salah satunya 
adalah kalkulus. Kalkulus dalam pendidikan matematika terbagi menjadi tiga, yaitu : kalkulus I, kalkulus II, dan kalkulus III.

Kalkulus merupakan mata kuliah yang cukup sulit bagi mahasiswa karena termasuk mata kuliah tingkat tinggi, sehingga tidak jarang mahasiswa yang kesulitan dalam mata kuliah kalkulus. Mulai dari kesulitan dalam konsep, kesulitan dalam menerapkan prinsip dan kesulitan dalam keterampilan (Dwidarti, dkk. 2019). Mata kuliah wajib dalam pendidikan matematika salah satunya adalah kalkulus. Kalkulus merupakan mata kuliah berkelanjutan sehingga pemahaman pada kalkulus I sangat diperlukan karena menjadi mata kuliah prasyarat untuk mengambil mata kuliah lain seperti, kalkulus II, analisis real, analisis komplek. Mata kuliah kalkulus termasuk mata kuliah yang sulit. Calculus have highly intrinsic complexity and often involves infinite process; therefore, students will encounter difficulties and obstacles while studying the subject, and will commit many errors when solving calculus problem, artinya Kalkulus memiliki kompleksitas intrinsik dan sering melibatkan proses penyelesaian yang takterbatas (Loc, 2014). Oleh karena itu, mahasiswa akan mengalami kesulitan saat mempelajari dan kesalahan saat mengerjakan soal kalkulus.

Materi yang dipelajari pada kalkulus I diantaranya adalah pertidaksamaan, nilai mutlak, induksi matematika, fungsi, sistem bilangan real. Beberapa materi tersebut yang di pelajari mendalam pada sekolah menengah atas salah satunya adalah pertidaksamaan. Data hasil ujian tengah semester dan ujian akhir menunjukkan bahwa nilai beberapa hasiswa pada mata kuliah kalkulus I kurang memuaskan dikarenakan beberapa mahasiswa melakukan kesalahan dalam menjawab soal materi pertidaksamaan (Ana Rahmawati, 2019). Pada kenyataan sudah dipelajari tetapi masih ada mahasiswa yang melakukan kesalahan dalam menjawab soal materi pertidaksaan pada mata kuliah kalkulus I.

Kesalahan adalah suatu penyimpangan terhadap jawaban yang sebenarnya (Ardiawan, Y, 2015). Kesulitan belajar matematika adalah kesulitan konsep. Kesalahan dalam mengerjakan soal matematika banyak yang mengalami kesalahan konsep dan pemahaman dalam belajar (Tall \& Razali, 1993). Ada tiga hal yang menyebabkan kesulitan belajar matematika adalah persepsi, intervensi dan ekstrafolasi (Layn \& Kahar, 2017). Pelaksanaan proses belajar akan sangat menentukan sejauh mana keberjasilan yang harus dicapai oleh suatu mata pelajaran matematika Terjadi kesalahan mahasiswa dalam menjawab soal disebabkan karena kurangnya dasar yang dimiliki. Kesalahan yang dilakukan oleh mahasiswa dalam menyelesaikan soal, bermula dari sekolah menengah atas (Mutakin, T. Z., 2015). Hal itu menunjukkan bahwa mahasiswa kesulitan dalam mengerjakan diatasi dengan melakukan identifikasi terhadap fenomena yang menunjukkan kemungkinan adanya kesulitan belajar mahasiswa (Indrayany, E. S., \& Lestari, F., 2019). Analisis kesalahan adalah upaya untuk mengamati, menemukan, dan mengklasifikasi kesalahan (Astuty \& Wijayanti, 2013). Kesalahan perlu dianalisis untuk mengetahui berbagai kesalahan yang dilakukan oleh mahasiswa, memperoleh jenis dan letak kesalahan, sehingga menemukan solusi untuk menangani kesalahan soal yang sulit. Kesalahan yang dilakukan mahasiswa perlu diidentifikasi terutama pada materi yang mengalami banyak kesalahan. 
Analisis Kesulitan Mahasiswa Pendidikan Matematika Menyelesaikan Soal Pada Mata Kuliah Kalkulus I, Fatma Ramadanti, Heni Pujiastuti

Kesulitan siswa dalam memecahkan soal dapat agar tidak terjadi terus-menerus dan tidak berdampak pada materi berikutnya.

Berdasarkan uraian di atas, dapat dipahami bahwa mahasiswa mengalami kesulitan dalam mempelajari dan manjawab soal kalkulus I. Sehubungan dengan hal itu, penulis mengadakan penelitian ini agar mahasiswa, dosen dan pembaca mengetahui kesulitan dalam belajar kalkulus I dan kesulitan mahasiswa dalam menjawab soal kalkulus I.

\section{METODE}

Metode yang digunakan dalam penelitian ini adalah jenis deskriptif dengan menggunakan pendekatan kualitatif. Penelitian ini menganalisis tentang kesulitan mahasiswa pendidikan matematika menyelesaikan soal pada mata kuliah kalkulus I. Pendekatan deskriptif adalah metode penelitian yang dilakukan untuk mengetahui keberadaan variabel, satu variabel atau lebih tanpa membuat perbandingan variabel dan mencari hubungan dengan variabel lain (Sugiyono, 2017:35). Penelitian kualitatif adalah penelitian yang ditunjukan untuk mendeskripsikan dan menganalisis fenomena, peristiwa, aktivitas sosial, sikap, kepercayaan, persepsi, pemikiran orang secara individual maupun kelompok (Syaodih, 2008: 60). Pemilihan metode kualitatif didasari oleh tujuan peneliti yang ingin mendeskripsikan secara mendalam tentang kesulitan mahasiswa pendidikan matematika menyelesaikan soal pada mata kuliah kalkulus I.

Penelitian ini dilaksanakan di Universitas Sultan Ageng Tirtayasa. Pengambilan subjek sesuai keadaan dan kondisi. Subjek dalam penelitian ini adalah beberapa mahasiswa pendidikan matematika Untirta semester 2 dengan kriteria : jawaban mewakili kesalahan yang banyak dilakukan oleh mahasiswa, jawabannya relatif relevan dengan soal, dapat berkomunikasi dengan baik. Teknik pengumpulan data yang digunakan pada penelitian ini adalah tes dan wawancara. Tes yang digunakan berupa soal uraian terkait materi pertidaksamaan, diberikan kepada semua mahasiswa pendidikan matematika yang mengambil mata kuliah kalkulus I.

Wawancara pada penelitian ini dengan mewawancarai subjek berdasarkan hasil tes tulis untuk mengklarifikasi jawaban tertulis dan memperoleh informasi penyebab mahasiswa melakukan kesalahan. Wawancara bersifat tidak terstruktur karena peneliti tidak menggunakan pedoman wawancara yang tersusun sistematis dan lengkap, pedoman wawancara yang digunakan berupa garis besar permasalahan yang ditanyakan (Sugiyono, 2016). Pertanyaan yang diberikan peneliti tidak sama untuk setiap subjek, tergantung dengan banyak informasi yang dibutuhkan. Sebelum peneliti menganalisis, peneliti memeriksa keabsahan data menggunakan triangulasi waktu untuk memperoleh data yang valid. Data yang sudah valid selanjutnya dianalisis kemudian ditarik sebuah kesimpulan. 


\section{HASIL}

Pada penelitian ini populasi yang dipilih adalah mahasiswa pendidikan matematika. Sampel penelitian sebanyak lima orang mahasiswa semester 2. Setiap mahasiswa diberikan soal yang sama, telah disiapkan oleh peneliti. Saat mengerjakan soal mahasiswa tidak diperbolehkan membuka buku catatan dan handphone. Setelah mahasiswa selesai mengerjakan soal, jawaban mahasiswa di identifikasi untuk mencari jawaban yang sesuai dengan kriteria sehingga mendapatkan informasi. Pengumpulan data dilakukan dengan melihat hasil tes dan wawancara.

Berikut soal Pertidaksamaan yang diberikan kepada sampel.

\begin{tabular}{|c|c|}
\hline No & Pertanyaan \\
\hline 1 & $\frac{2}{3 x}<4$ \\
\hline 2 & $\left|x^{2}-1\right|<3$ \\
\hline 3 & $|2 x-1| \geq|x-1|$ \\
\hline 4 & $\frac{x-2}{4} \leq \frac{x^{2}}{x+1}$ \\
\hline 5 & $|x-1|+|2 x-1| \leq 2$ \\
\hline
\end{tabular}

Berdasarkan kriteria, peneliti mendapatkan dua sampel yang sesuai. Dua sampel dinamai dengan sampel X dan Sampel Y. Pada waktu yang berbeda, peneliti memberikan soal yang berbeda pada sampel X dan sampel Y. Lalu hasil tes sampel pertama dan kedua dibandingkan oleh peneliti. Selanjutnya, peneliti melakukan wawancara dari hasil tes yang dilakukan. Jika hasil tes pertama dan hasil tes kedua sama maka, data yang didapatkan sudah valid. Peneliti dapat menganalisis data tersebut.

Berdasarkan hasil tes pertama, jawaban tes dan hasil wawancara. Berikut analisis kesalahan mahasiswa dalam menjawab soal pertidaksamaan yang didapat peneliti :

\section{Sampel $\mathbf{X}$}

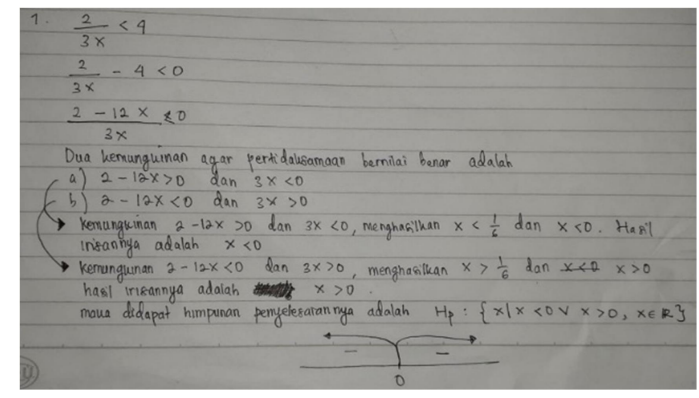

Gambar 1. Jawaban no 1

Diketahui beberapa kesalahan yang dilakukan mahasiswa sampel X, yaitu : 
a. Kesalahan menentukan hasil irisan $x>\frac{1}{6}$ dan $x>0$. Seharusnya hasil irisan dari $x>\frac{1}{6}$ dan $x>0$ adalah $x>\frac{1}{6}$ sedangkan, jawaban yang tertera $x>0$. Berdasarkan hasil wawancara, diketahui bahwa mahasiswa kurang memahami konsep irisan sehingga, saat menentukan irisan dengan model yang berbeda kebingungan untuk menentukan irisan.

b. Kesalahan menentukan himpunan penyelesaian. Hal ini terjadi karena kesalahan menentukan hasil irisan.

c. Kesalahan menggambarkan garis bilangan. Hal ini terjadi karena kesalahan menentukan irisan yang membuat terjadi kesalahan himpunan penyelesaian.

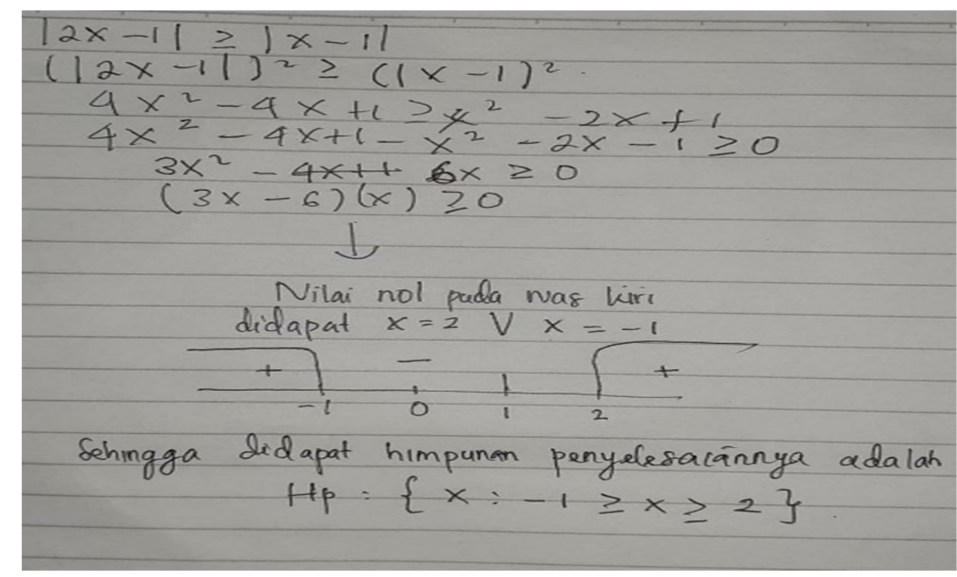

Gambar 2. Jawaban no 3

Diketahui beberapa kesalahan yang dilakukan mahasiswa sampel X, yaitu :

a. Kesalahan menentukan nilai pembuat nol di ruas kiri. Jawaban subjek $\mathrm{X}$, nilai $x$ adalah 2 dan -1 , seharusnya nilai $x$ adalah 2 dan 0 . Ketika diwawancarai subjek $\mathrm{X}$ yakin bahwa jawabannya sudah tepat sehingga dapat diketahui bahwa subjek mengalami kesalahan karena subjek X kurang memahami jika pertidaksamaan kuadrat diubah bentuk, subjek X mengira bahwa nilai $x$ sama dengan -1 .

b. Kesalahan menentukan nilai pembuat nol pada garis bilangan. Subjek X melakukan kesalahan karena subjek $\mathrm{X}$ melakukan kesalahan pada kesalahan a sehingga, nilai $x$ pada garis bilangan kurang tepat.

c. Kesalahan dalam menentukan daerah penyelesaian pada garis bilangan dan kesalahan menentukan himpunan penyelesaian karena kesalahan yang dilakukan subjek X sebelumnya. 


\section{Sampel Y}

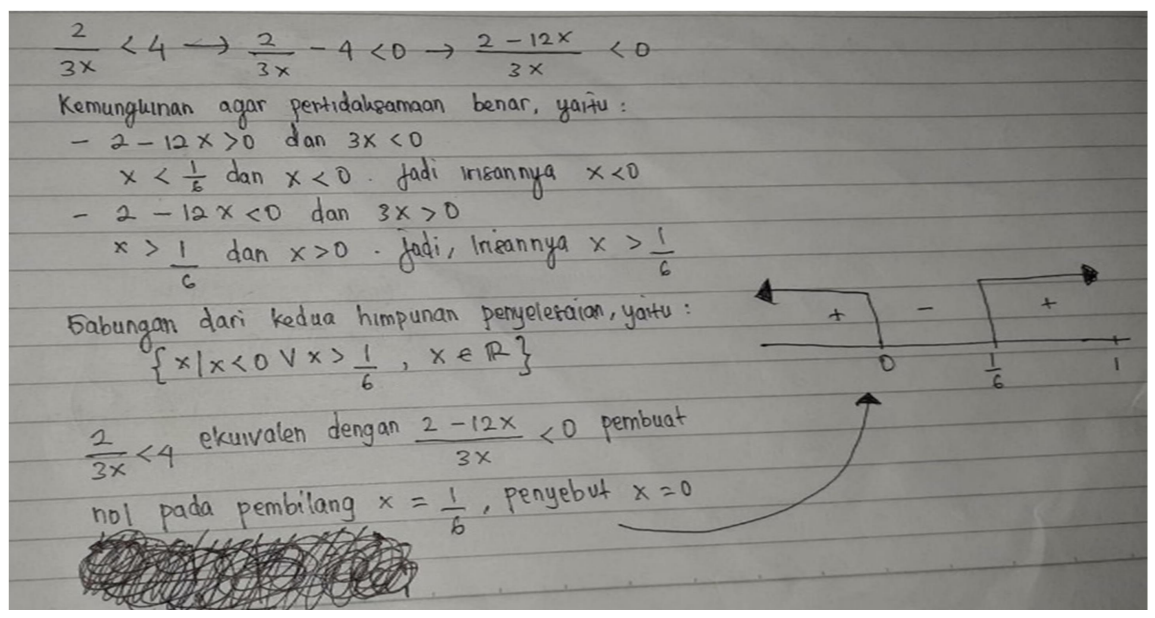

Gambar 3. Jawaban no 1

Diketahui beberapa kesalahan yang dilakukan mahasiswa sampel Y, yaitu :

a. Kesalahan menggambarkan menentukan positif negatif pada garis bilangan. Setelah diwawancara diketahui bahwa mahasiswa kurang memahami cara menentukan daerah pada garis bilangan dan kebingungan menentukan positif negatif.

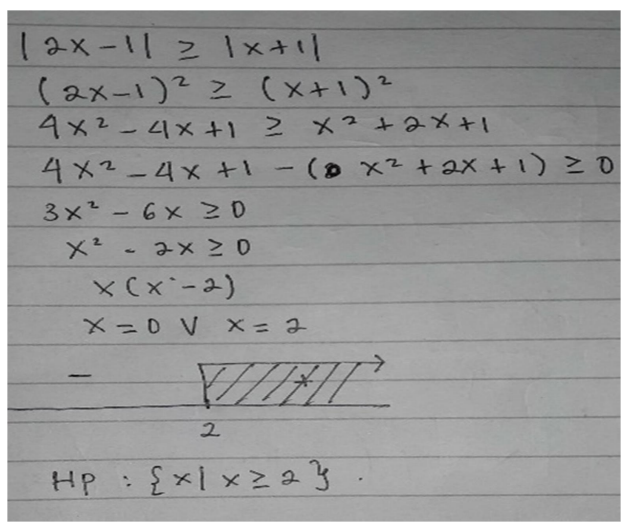

Gambar 4. Jawaban no 3

Diketahui beberapa kesalahan yang dilakukan mahasiswa sampel Y, yaitu :

a. Kesalahan menentukan nilai pembuat nol pada garis bilangan. Nilai pembuat nol yang dituliskan sudah benar, yaitu $x=0$ dan $x=2$ tetapi, subjek Y tidak menuliskan nilai $x=0$ karena menurut subjek Y itu tidak perlu dituliskan karena nilainya nol. Berdasarkan peryataan yang diberikan subjek Y disimpulkan bahwa subjek kurang memahami materi pertidaksamaan yang mendasar.

b. Kesalahan menentukan tanda interval, karena subjek Y melakukan kesalahan a.

c. Kesalahan menentukan daerah penyelesaian pada garis bilangan, karena subjek Y melakukan kesalahan a dan b. mengakibatkan himpunan penyelesaian kurang tepat. 
Berdasarkan analisis yang dilakukan peneliti didapatkan kesimpulan kesalahan sampel X dan sampel Y.

\section{Tabel 1.}

Kesalahan sampel $X$ dan sampel $Y$.

\begin{tabular}{|c|c|}
\hline Kesalahan Sampel X & Kesalahan Sampel Y \\
\hline Kesalahan menentukan hasil irisan & Kesalahan menggambarkan garis bilangan \\
\hline $\begin{array}{c}\text { Kesalahan menentukan himpunan } \\
\text { penyelesaian }\end{array}$ & $\begin{array}{c}\text { Kesalahan menentukan positif dan negatif } \\
\text { pada garis bilangan }\end{array}$ \\
\hline $\begin{array}{c}\text { Kesalahan menentukan nilai pembuat nol } \\
\text { pada garis bilangan }\end{array}$ & $\begin{array}{c}\text { Kesalahan menentukan himpunan } \\
\text { penyelesaian }\end{array}$ \\
\hline $\begin{array}{c}\text { Kesalahan menentukan daerah } \\
\text { penyelesaian garis bilangan }\end{array}$ & Kesalahan menentukan tanda interval \\
\hline $\begin{array}{c}\text { Kesalahan menggambarkan garis } \\
\text { bilangan }\end{array}$ & Kesalahan menggambarkan garis bilangan \\
\hline $\begin{array}{c}\text { Kesalahan menentukan nilai pembuat nol } \\
\text { Kesalahan menentukan daerah } \\
\text { penyelesaian garis bilangan }\end{array}$ \\
\hline
\end{tabular}

Berdasarkan tabel 1, sampel X melakukan 6 kesalahan dan sampel Y melakukan 6 kesalahan. Menurut wawancaa yang telah dilakukan, kesalahan sampel $\mathrm{X}$ dan sampel $\mathrm{Y}$ hampir sama yaitu, kurang memahami konsep pertidaksamaan dan tidak ingat konsep dasar matematika. Oleh karena itu, kesalahan terjadi dalam mengerjakan soal.

Kesalahan mahasiswa dalam mengerjakan soal terjadi karena kurang memahami materi pertidaksamaan dan kurang teliti (Ana Rahmawati, 2019). Pada saat mengerjakan mahasiswa kebingungan langkah-langkah pengerjaan dan konsep dasar seperti menentukan irisan dan menentukan tanda interval akibatnya mahasiswa kebingungan mengganggu konsentrasi sehingga kurang teliti. Penyebab terjadi kesalahan mahasiswa dalam menyelesaikan soal Kalkulus I adalah mahasiswa tidak menghafal rumus, kurang teliti, tidak ada persiapan, tidak ingat cara penyelesaiannya (Abidin, Z., 2012).

\section{KESIMPULAN}

Berdasarkan hasil analisis data di atas, disimpulkan bahwa sampel X melakukan 6 kesalahan yaitu kesalahan menentukan hasil irisan, kesalahan menentukan himpunan penyelesaian, kesalahan menggambarkan garis bilangan, kesalahan menentukan nilai pembuat nol, kesalahan menentukan nilai pembuat nol pada garis bilangan, kesalahan menentukan daerah penyelesaian garis bilangan. Sampel Y melakukan 6 kesalahan yaitu kesalahan menggambarkan garis bilangan, kesalahan menentukan positif negatif pada garis bilangan, kesalahan menentukan tanda interval, kesalahan menentukan himpunan penyelesaian, kesalahan menentukan daerah penyelesaian garis bilangan. Kesalahan dari kedua sampel hampir sama yaitu kurang memahami konsep pertidaksamaan dan tidak ingat konsep dasar. 
Setelah deskripsi kesalahan mahasiswa dalam mengerjakan soal pada mata kuliah kalkulus I materi pertidaksamaan, sebaiknya dosen memberikan arahan kepada mahasiswa untuk tetap mengingat konsep dasar matematika, memahami konsep materi sebelum pertidaksamaan dan memahami konsep materi pertidaksamaan. Guna menindaklanjuti penelitian ini, meneliti analisis kesalahan lebih lanjut dan pemberian scaffolding. Penelitian ini terbatas hanya Universitas Sultan Ageng Tirtayasa, harapannya penelitian ini berkembang untuk universitas lainnya.

\section{DAFTAR PUSTAKA}

Abidin, Z. (2012). Analisis Kesalahan Mahasiswa Prodi Pendidikan Matematika Fakultas Tarbiyah Iain Ar-Raniry Dalam Mata Kuliah Trigonometri Dan Kalkulus 1. Jurnal Ilmiah DIDAKTIKA, XIII(1), 183-196.

Ana Rahmawati. (2019). Analisis Kesalahan Mahasiswa Pendidikan Matematika Dalam Menyelesaikan Soal Pertidaksamaan Pada Mata Kuliah Kalkulus I Ana. Journal of Chemical Information and Modeling, 53(9), 1689-1699. https://doi.org/10.1017/CBO9781107415324.004

Ardiawan, Y. (2015). Analisis Kesalahan Mahasiswa dalam Menyelesaikan Soal Induksi Matematika di IKIP PGRI Pontianak. Jurnal Pendidikan Informatika Dan Sains, 4(1), 147-163.

Dwidarti, Ufi. dkk. (2019). Analisis Kesulitan Siswa Dalam Menyelesaikan Soal Cerita Pada Materi Himpunan. Jurnal Cendekia : Jurnal Pendidikan Matematika

Indrayany, E. S., \& Lestari, F. (2019). Analisis kesulitan siswa SMP dalam memecahkan masalah geometri dan faktor penyebab kesulitan siswa ditinjau dari teori van hiele. Jurnal Math Educator Nusantara: Wahana Publikasi Karya Tulis Ilmiah Di Bidang Pendidikan Matematika, 5(2), 109-123. https://doi.org/10.29407/jmen.v5i2.13729

Layn, M. R., \& Kahar, M. S. (2017). Analisis Kesalahan Siswa dalam Menyelesaikan Soal Cerita Matematika. Jurnal Math Educator Nusantara: Wahana Publikasi Karya Tulis Ilmiah Di Bidang Pendidikan Matematika, 3(2).

Loc, N. P. and T. C. T. H. (2014). A survey of 12th grade Students' Errors In Solving Calculua Problem. International Journal of Scientific and Technology Research, 3(6).

Mutakin, T. Z. (2015). Analisis Kesulitan Belajar Kalkulus 1 Mahasiswa Teknik Informatika. Formatif: Jurnal Ilmiah Pendidikan MIPA, 3(1), 49-60. https://doi.org/10.30998/formatif.v3i1.113

Sugiono. (2016). Metode Penelitian Kuantitatif. Bandung: Alfabeda.

Sugiono. (2017). Metode Penelitian Kualitatif, Kuantitatif dan R\&D. Bandung: Alfabeda.

Sukmadinata, N. syaodih. (2008). Metode Penelitian Pendidikan. Bandung: PT. Remaja Rosdakarya.

Tall, D. (1993). Diagnosis Students Difficulties in Learning Mathematics. International Journal of Mathematics Education in Science \& Technology. 